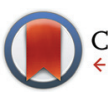

CrossMark \&lick for updates

Cite this: Dalton Trans., 2015, 44 16802

Received 15th June 2015, Accepted 20th August 2015

DOI: $10.1039 / \mathrm{c} 5 \mathrm{dt} 02276 \mathrm{~b}$

www.rsc.org/dalton

\title{
Synthesis and post-synthetic modification of amine-, alkyne-, azide- and nitro-functionalized metal-organic frameworks based on DUT-5†
}

\author{
Meike A. Gotthardt, ${ }^{a}$ Sylvain Grosjean, ${ }^{b, c}$ Tobias S. Brunner, ${ }^{d}$ Johannes Kotzel, ${ }^{a}$ \\ Andreas M. Gänzler, ${ }^{a}$ Silke Wolf, ${ }^{d}$ Stefan Bräse ${ }^{\star b, e}$ and Wolfgang Kleist*a,f
}

Functionalized 4,4'-biphenyldicarboxylic acid molecules with additional amine, alkyne, azide or nitro groups were prepared and applied in the synthesis of novel metal-organic frameworks and mixed-linker metal-organic frameworks isoreticular to DUT-5. The properties of the frameworks could be tuned by varying the number of functional groups in the materials and the amine groups were employed in postsynthetic modification reactions without changing the framework structure or significantly decreasing the porosity of the materials.

\section{Introduction}

Due to their defined structures, high specific surface areas and chemical diversity, research effort on metal-organic frameworks (MOFs) ${ }^{1-5}$ has increased over the last years. One focus is on the incorporation of linker molecules bearing a functional side group into a known framework structure resulting in so-called isoreticular metal-organic frameworks. This can be achieved either by direct synthesis ${ }^{6-12}$ or via post-synthetic modification (PSM) ${ }^{13-18}$ of the frameworks. The most prominent example for the direct synthesis is the IRMOF series based on MOF-5. ${ }^{19,20}$ MIL-53(Al) ${ }^{21}$ (MIL: Matériaux de l'Institut Lavoisier) has also been synthesized using several functionalized terephthalate linkers. ${ }^{22-26}$ The number of functional groups in MOFs can be adjusted by synthesizing mixed-linker metal-organic frameworks (MIXMOFs) with defined ratios of

\footnotetext{
${ }^{a}$ Institute for Chemical Technology and Polymer Chemistry, Karlsruhe Institute of Technology (KIT), Engesserstr. 20, 76131 Karlsruhe, Germany

${ }^{b}$ Institute of Organic Chemistry, Karlsruhe Institute of Technology (KIT), Fritz-HaberWeg 6, 76131 Karlsruhe, Germany. E-mail: stefan.braese@kit.edu;

Fax: +49721 60848581; Tel: +4972160842903

${ }^{c}$ Soft Matter Synthesis Lab, Institute for Biological Interfaces, Karlsruhe Institute of Technology (KIT), Hermann-von-Helmholtz-Platz 1, 76344 Eggenstein-Leopoldshafen, Germany

${ }^{d}$ Institute for Inorganic Chemistry, Karlsruhe Institute of Technology (KIT),

Engesserstr. 15, 76131 Karlsruhe, Germany

${ }^{e}$ Institute of Toxicology and Genetics, Karlsruhe Institute of Technology (KIT), Hermann-von-Helmholtz-Platz 1, 76344 Eggenstein-Leopoldshafen, Germany ${ }^{f}$ Institute of Catalysis Research and Technology, Karlsruhe Institute of Technology (KIT), Hermann-von-Helmholtz-Platz 1, 76344 Eggenstein-Leopoldshafen, Germany. E-mail: wolfgang:kleist@kit.edu; Fax: +49721 60844820; Tel: +4972160847989 $\dagger$ Electronic supplementary information (ESI) available: Experimental details, additional results and figures. See DOI: 10.1039/c5dt02276b
}

functionalized and unfunctionalized linker molecules. ${ }^{27-33}$ MIXMOFs have the advantage that their properties, e.g. specific surface area, thermal stability and basicity, can be tuned depending on the linker ratio. ${ }^{27-29}$ Moreover, the number of functional groups in the framework materials influences the interaction with guest molecules, which can be beneficial for gas adsorption applications. ${ }^{34}$

When linker molecules with more complex side chains are used during synthesis, the formation of the framework might be prevented due to sterical hindrance or undesired side reactions of these functional groups with framework metal atoms, therefore, changing the target structure. In those cases, the functionalities can be incorporated in the MOF structure using the post-synthetic modification approach, in which a more complex organic group is covalently anchored to the side functionality of the linker after framework formation. The approach has often been applied to modify amine functionalities, e.g. with anhydrides, ${ }^{35,36}$ aldehydes ${ }^{13}$ or isocyanates. ${ }^{37}$ Azide $^{38-40}$ or alkyne ${ }^{41}$ groups have also been used for postsynthetic click reactions. The introduced side chains can for example enhance the gas adsorption ${ }^{20,26,42}$ and separation ${ }^{43,44}$ properties of a framework or they can be exploited as active sites in heterogeneous catalysis. ${ }^{36,45-47}$

We previously modified the metal-organic framework MIL-53- $\mathrm{NH}_{2}(\mathrm{Al})$ with maleic anhydride, which resulted in a chelating side chain that was used to immobilize Pd(II) complexes. ${ }^{48}$ During this process, a drastic decrease in specific surface area from approx. $1000 \mathrm{~m}^{2} \mathrm{~g}^{-1}$ to only $85 \mathrm{~m}^{2} \mathrm{~g}^{-1}$ has been observed. Owing to this fact, in a second study mixedlinker metal-organic frameworks with a defined ratio of functionalized and unfunctionalized linker molecules were applied as starting materials for PSM. ${ }^{49}$ Although pore blocking could 
be minimized due to the dilution of the amine groups, the specific surface area was still only approx. $500 \mathrm{~m}^{2} \mathrm{~g}^{-1}$ after PSM. Furthermore, as a consequence of the small size of the terephthalate linkers, also the diameter of the resulting pores in mixed-linker MIL-53(Al) is comparatively small $(<1 \mathrm{~nm})$, thus, limiting the range of potential guest molecules for PSM or applications in separation and catalysis.

To further increase the accessible pore volume and to enable more complex modification routes, the incorporation of longer linker molecules into the framework structure might be beneficial. There are already examples in literature for materials that feature structures isoreticular to MIL-53(Al) but larger pore dimensions. MOF- $253^{50}$ could be synthesized with 2,2'-bipyridine-4,4'-dicarboxylate linkers, which were postsynthetically modified with palladium, ${ }^{50}$ copper $^{50}$ and ruthenium $^{51}$ complexes for applications in catalysis. ${ }^{51,52} 4,4^{\prime}$-Biphenyldicarboxylate (BPDC) was employed as linker molecule in the synthesis of the porous framework DUT-5 (DUT: Dresden University of Technology). ${ }^{53}$ DUT-5 consists of $\mathrm{Al}-\mathrm{OH}$ chains, which are connected by the linker molecules resulting in a three-dimensional framework structure, in which the aluminum ions are coordinated to six oxygen atoms (space group Imma; Scheme 1). The resulting material is thermally stable to approx. $400{ }^{\circ} \mathrm{C}$ and has a specific surface area of $S_{\text {BET }} \sim 1610 \mathrm{~m}^{2} \mathrm{~g}^{-1}$. In contrast to MIL-53(Al), which interacts with different substrates inside the pores by changing its pore geometry (breathing effect), ${ }^{21}$ DUT-5 is a rigid framework.

An isoreticular framework DUT-5-SO $\mathrm{S}_{2}$ with 4,4'-dibenzoic acid-2,2'-sulfone linkers has been synthesized and was applied in the gas phase adsorption of alkanes, alkenes and aromatics. $^{54}$ Recently, DUT-5-amine and DUT-5-nitro were synthesized successfully applying 2-amine-4,4'-biphenyldicarboxylic acid and 2-nitro-4,4'-biphenyldicarboxylic acid in the framework synthesis. ${ }^{55}$ However, so far none of the frameworks bearing free functional groups have been applied in post-synthetic modification reactions. In the present work, functionalized 4,4'-biphenyldicarboxylic acid molecules with

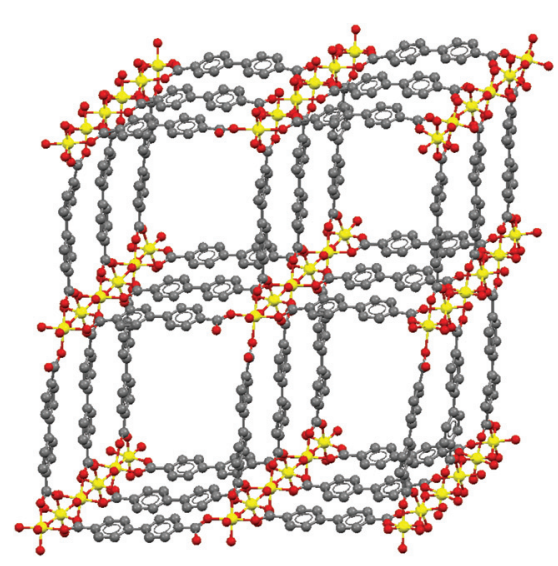

Scheme 1 Schematic representation of the structure of the metal organic framework DUT-5; grey: $\mathrm{C}$, red: $\mathrm{O}$, yellow: $\mathrm{Al}$; pore diameter: $19.2 \times 22.7 \AA$ A ; space group: Imma.

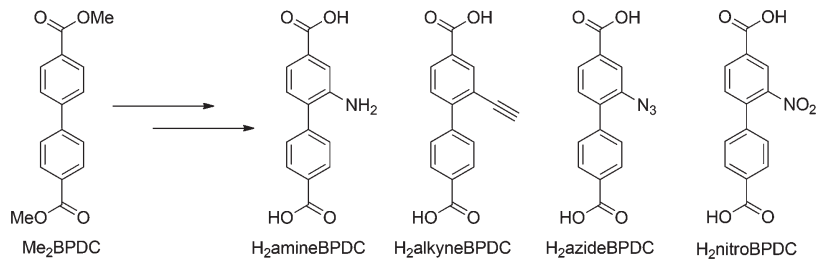

Scheme 2 Functionalized 4,4'-biphenyldicarboxylic acid molecules with an additional amine $\left(\mathrm{H}_{2}\right.$ amineBPDC), alkyne $\left(\mathrm{H}_{2}\right.$ alkyneBPDC), azide ( $\mathrm{H}_{2}$ azideBPDC) or nitro $\left(\mathrm{H}_{2}\right.$ nitroBPDC) group.

an additional amine, alkyne, azide or nitro group were used. Since none of these linkers are commercially available, they were synthesized in a straightforward multi-step synthesis from dimethyl biphenyldicarboxylate ( $\mathrm{Me}_{2} \mathrm{BPDC}$, Scheme 2 ) as a single cheap starting material.

The functionalized linker molecules were applied in the formation of DUT-5-amine, DUT-5-alkyne, DUT-5-azide and DUT-5-nitro. Moreover, mixed-linker metal-organic frameworks with a defined number of functionalized and unfunctionalized linkers were synthesized. The novel mixed-linker framework materials were thoroughly characterized and aminefunctionalized MIXDUT-5-amine(50) was successfully modified in post-synthetic modification reactions with maleic anhydride, salicylaldehyde and 2-pyridinecarboxaldehyde.

\section{Results and discussion}

\section{Synthesis}

The introduction of additional side groups at the linker molecules is essential to tune the properties of metal-organic frameworks and to enable post-synthetic modification of the materials. To obtain functionalized metal-organic frameworks based on DUT-5, which is known from literature, ${ }^{53} 4,4^{\prime}$-biphenyldicarboxylic acid molecules with an additional amine, alkyne, azide or nitro group (Scheme 3 and ESI $\dagger$ ) were synthesized.

The synthetic strategy was designed to minimize the number of synthetic steps and, thus, all four linkers could be obtained in two to five steps from a commercially available starting material. Therefore, the four linker molecules were synthesized within only eight steps in total. The first key intermediate, dimethyl 2-nitrobiphenyldicarboxylate (1), was prepared by nitration of $\mathrm{Me}_{2} \mathrm{BPDC}$ following a described procedure under standard nitration conditions. ${ }^{56}$ The nitrofunctionalized linker $\mathrm{H}_{2}$ nitroBPDC was obtained by hydrolysis of the ester groups of (1) under basic conditions. The second key intermediate of the synthesis, dimethyl 2-aminobiphenyldicarboxylate (2), was prepared by reduction of (1) with $\mathrm{Pd} / \mathrm{C}$ in $\mathrm{H}_{2}$ atmosphere. The amine-functionalized linker $\mathrm{H}_{2}$ amineBPDC was also obtained by basic hydrolysis of the dimethyl ester precursor 2. The azide-functionalized linker $\mathrm{H}_{2}$ azideBPDC was synthesized from $\mathrm{H}_{2}$ amineBPDC using a mild and efficient procedure applying tert-butyl nitrite $\left({ }^{t} \mathrm{BuONO}\right)$ for the 
(a). $\mathrm{KOH}, \mathrm{THF} / \mathrm{H}_{2} \mathrm{O}$, reflux, $74 \%$

(b). $\mathrm{Pd} / \mathrm{C}, \mathrm{H}_{2}, \mathrm{THF}$, r.t., $91 \%$

(c). $\mathrm{KOH}, \mathrm{THF} / \mathrm{H}_{2} \mathrm{O}$, reflux, $95 \%$

(d). $t \mathrm{BuONO}, \mathrm{THF}$, then $\mathrm{TMS}-\mathrm{N}_{3}, 0^{\circ} \mathrm{C}$ to r.t., $97 \%$

(e). $\mathrm{NaNO}_{2}$, aq. $\mathrm{HCl}, 0^{\circ} \mathrm{C}$, then $\mathrm{Nal}, 0^{\circ} \mathrm{C}, 64 \%$

(f). $\mathrm{TMSA}, \mathrm{PdCl}_{2}\left(\mathrm{PPh}_{3}\right)_{2}, \mathrm{Cul} \mathrm{Et}_{3} \mathrm{~N} / \mathrm{THF}$, r.t., $91 \%$

(g). $\mathrm{KOH}, \mathrm{THF} / \mathrm{H}_{2} \mathrm{O}$, r.t., $92 \%$.

(1)

formation of a diazonium salt and its subsequent substitution with azidotrimethylsilane (TMS- $\mathrm{N}_{3}$ ). ${ }^{57}$ The alkyne-functionalized linker $\mathrm{H}_{2}$ alkyneBPDC was prepared in three steps from the key intermediate 2 . In a first step, the dimethyl ester 2-iodo derivative (3) was obtained by nucleophilic substitution with sodium iodide via the corresponding diazonium salt. Direct coupling of trimethylsilylacetylene (TMSA) with 3 catalyzed by $\mathrm{Pd} / \mathrm{Cu}$ led to the formation of the TMS-protected alkynyl derivative (4). The final deprotection step of the acid and the alkyne groups was performed in basic media resulting in $\mathrm{H}_{2}$ alkyneBPDC.

Applying those linker molecules, single-linker DUT-5amine, DUT-5-alkyne, DUT-5-nitro and DUT-5-azide were synthesized. In addition, mixed-linker metal-organic frameworks with varying ratios of functionalized and unfunctionalized linker molecules were prepared (denoted as "MIXDUT-5-functionality $(x)$ ", where $x$ is the amount of functionalized linker in mol\%). Moreover, a MIXDUT-5-amine(33)-alkyne(33) with three different linker molecules was synthesized. In contrast to the solvothermal route used in literature, ${ }^{53}$ all reactions were performed at ambient pressure (see ESI $\dagger$ ), therefore simplifying the up-scaling of the reaction, which is important for potential applications.

\section{Characterization}

The X-ray diffractogram of DUT- 5 matched the one reported in literature ${ }^{53}$ very well confirming the successful formation of the framework structure under ambient pressure. Furthermore, the structures of the functionalized (Fig. 1) and mixedlinker (Fig. 2 and S1-S4 $\dagger$ ) materials proved to be isoreticular to DUT-5, thus, demonstrating that the functional side groups did not prevent the formation of the framework. However, the intensity of the reflections for the azide-functionalized frameworks was lower and the reflections were significantly broader indicating a decreased crystallinity of the materials or amorphous contributions.

ATR-IR spectroscopy was applied to exclude the presence of residual free acid molecules or solvent molecules ( $N, N$-dimethylformamide) in the pores of the frameworks. Moreover, ATR-IR was used to ascertain that the functional groups were stable under the synthesis conditions and present in the

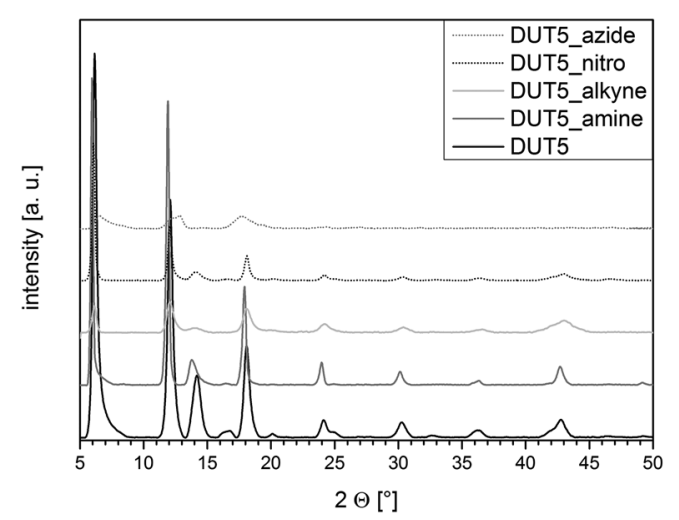

Fig. 1 XRD patterns of DUT-5 and functionalized materials based on DUT-5.

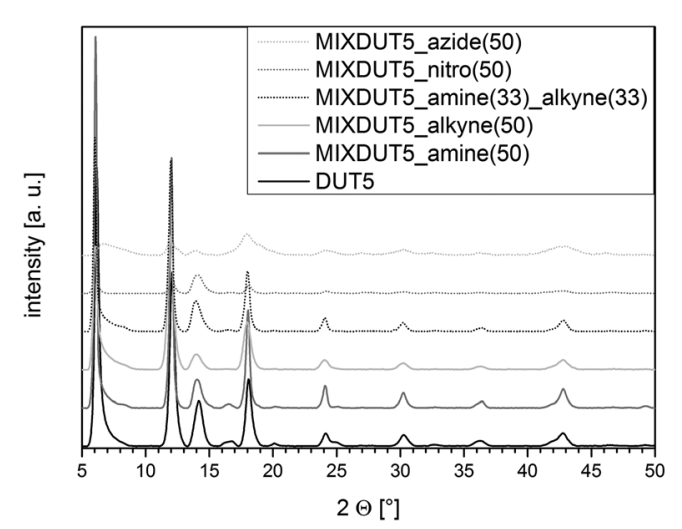

Fig. 2 XRD patterns of DUT-5 and mixed-linker metal-organic frameworks based on DUT-5.

resulting materials (Fig. S7-S11†). The spectra did not show any bands that could be ascribed to the $\mathrm{C}=\mathrm{O}$ vibrations of free acid molecules or DMF. Therefore, IR analyses suggest that the pore system of the functionalized materials is not blocked by residual molecules and that the side groups should be accessible for post-synthetic modification. The N-H stretching vibrations of the amine functionalities $\left(3485 \mathrm{~cm}^{-1}\right.$ and 
$3380 \mathrm{~cm}^{-1}$ ) and the $\mathrm{C} \equiv \mathrm{C}-\mathrm{H}$ stretching vibration of the alkyne functionalities $\left(3290 \mathrm{~cm}^{-1}\right.$ ) have a low intensity but can be observed in the corresponding spectra. Likewise, the nitro functionalities show characteristic bands at $1533 \mathrm{~cm}^{-1}$ and $1355 \mathrm{~cm}^{-1}$. Those observations clearly prove the successful incorporation of the functionalized linker molecules into the frameworks. However, the azide band (around $2120 \mathrm{~cm}^{-1}$ ) was barely visible, which led to the assumption that the azide functionality might not be stable under the applied reaction conditions. Instead, an additional band at $3436 \mathrm{~cm}^{-1}$ was observed which suggested the formation of a carbazole. This transformation of $\mathrm{H}_{2}$ azideBPDC has recently also been reported in literature when high temperatures $\left(>80{ }^{\circ} \mathrm{C}\right)$ were used during the synthesis of the Zr-based framework UiO-67. ${ }^{58}$ The formation of the carbazole led to a slightly bent linker molecule and therefore a changed geometry, which might be the reason for the low crystallinity of the azide-containing MOFs.

Nitrogen physisorption measurements were performed to determine the accessible pore volumes and specific surface areas. The adsorption and desorption isotherms of all materials can be found in the ESI (Fig. S13-S18†). A specific surface area of $1880 \mathrm{~m}^{2} \mathrm{~g}^{-1}$ and a micropore volume of $0.61 \mathrm{~cm}^{3} \mathrm{~g}^{-1}$ were established for DUT-5, which is in good agreement with the values $\left(S_{\mathrm{BET}}=1613 \mathrm{~m}^{2} \mathrm{~g}^{-1}\right.$; pore volume $=$ $0.81 \mathrm{~cm}^{3} \mathrm{~g}^{-1}$ ) reported in literature. ${ }^{53}$ The surface areas of the amine- and alkyne-functionalized MOFs were only slightly lower $\left(S_{\text {BET }}(\right.$ DUT-5-amine $)=1570 \mathrm{~m}^{2} \mathrm{~g}^{-1} ; S_{\text {BET }}($ DUT-5-alkyne $)=$ $1270 \mathrm{~m}^{2} \mathrm{~g}^{-1}$; Table 1) proving again the formation of the porous DUT-5 structure. However, the specific surface areas of DUT-5-azide $\left(540 \mathrm{~m}^{2} \mathrm{~g}^{-1}\right.$; Table S5 $\left.\dagger\right)$ and DUT-5-nitro $\left(550 \mathrm{~m}^{2}\right.$ $\mathrm{g}^{-1}$ ) were significantly lower, which in combination with the XRD data indicates that the formation of an extensive threedimensional framework structure was not successful.

For the MIXDUT-5-amine $(x)$ frameworks the specific surface areas ranged from $1600 \mathrm{~m}^{2} \mathrm{~g}^{-1}$ to $1630 \mathrm{~m}^{2} \mathrm{~g}^{-1}$ and were, thus, between the values of pure DUT-5 and pure DUT-5-amine (Table 2). With the exception of the azide- and nitro-functionalized frameworks, the new materials all exhibited high specific surface areas from $1350 \mathrm{~m}^{2} \mathrm{~g}^{-1}$ for MIXDUT-5-alkyne(50) to $1630 \mathrm{~m}^{2} \mathrm{~g}^{-1}$ for MIXDUT-5-amine(50) and MIXDUT-5-amine (33)-alkyne(33) and featured large micropore volumes, which is essential for post-synthetic modification at the functional side groups.

To probe the thermal stability of the frameworks, thermogravimetric analyses were carried out in air (Table 3 and

Table 1 Specific surface areas and micropore volumes of DUT-5 and functionalized DUT-5

\begin{tabular}{lll}
\hline Material & $S_{\text {BET }}\left[\mathrm{m}^{2} \mathrm{~g}^{-1}\right]$ & Micropore volume $\left[\mathrm{cm}^{3} \mathrm{~g}^{-1}\right]$ \\
\hline DUT-5 & 1880 & 0.61 \\
DUT-5-amine & 1570 & 0.58 \\
DUT-5-alkyne & 1270 & 0.40 \\
DUT-5-nitro & 550 & 0.15
\end{tabular}

Table 2 Specific surface areas and micropore volumes of MIXDUT-5functionality $(x)$ materials; $x$ : amount of functionalized linker molecules applied in the synthesis in mol\%

\begin{tabular}{lll}
\hline Material & $\begin{array}{l}S_{\mathrm{BET}} \\
{\left[\mathrm{m}^{2} \mathrm{~g}^{-1}\right]}\end{array}$ & $\begin{array}{l}\text { Micropore volume } \\
{\left[\mathrm{cm}^{3} \mathrm{~g}^{-1}\right]}\end{array}$ \\
\hline MIXDUT-5-amine(25) & 1600 & 0.54 \\
MIXDUT-5-amine(50) & 1630 & 0.58 \\
MIXDUT-5-amine(75) & 1630 & 0.59 \\
MIXDUT-5-alkyne(25) & 650 & 0.17 \\
MIXDUT-5-alkyne(50) & 1350 & 0.42 \\
MIXDUT-5-alkyne(75) & 970 & 0.29 \\
MIXDUT-5-amine(33)-alkyne(33) & 1630 & 0.56
\end{tabular}

Table 3 Thermal stability of functionalized DUT-5 frameworks and mixed-linker frameworks in air

Thermal stability $\left[{ }^{\circ} \mathrm{C}\right]$

DUT-5

MIXDUT-5-amine(25)

450

MIXDUT-5-amine(50)

MIXDUT-5-amine(75)

420

DUT-5-amine

400

MIXDUT-5-alkyne(25)

390

370

MIXDUT-5-alkyne(50) 420

MIXDUT-5-alkyne(75) 400

DUT-5-alkyne 390

MIXDUT-5-nitro(50) 380

DUT-5-nitro $\quad 340$

MIXDUT-5-amine(33)-alkyne(33) 410

Fig. S21-S30 $\dagger$ ). In literature, a thermal stability of up to $430{ }^{\circ} \mathrm{C}$ was reported for DUT-5. ${ }^{53}$ The measurements performed in the present work showed the stability of DUT-5 up to $450{ }^{\circ} \mathrm{C}$, therefore, also supporting the successful formation of the DUT-5 structure. The functionalized frameworks showed a reduced but still relatively high thermal stability of $340{ }^{\circ} \mathrm{C}$ (DUT-5-nitro), $370{ }^{\circ} \mathrm{C}$ (DUT-5-amine and DUT-5-azide) and $390{ }^{\circ} \mathrm{C}$ (DUT-5-alkyne). By introducing different amounts of the functionalized linker molecules, the thermal stability of the MIXDUTs could be tuned following a trend depending on the linker ratio. With increasing amount of amine functionalities in the frameworks, the thermal stability was gradually reduced from $450{ }^{\circ} \mathrm{C}$ to $370{ }^{\circ} \mathrm{C}$ (Fig. 3 and Table 3). This trend has previously been reported for amine-functionalized mixedlinker MOFs based on MIL-53(Al) ${ }^{29}$ and is a qualitative proof for the linker ratio incorporated in the MIXDUTs. A similar trend was also observed for the alkyne-, azide- and nitro-functionalized MIXDUT-5 materials (Table 3 and Fig. S23-S30†).

Additionally, TG-IR measurements were performed (Fig. S33 and S34 $\dagger$ ) to confirm the successful incorporation of a defined number of the amine-functionalized linker molecules into the MIXDUT-5-amine $(x)$ materials. The $\mathrm{NO}_{2}$ band in the IR spectra, which originated from oxidation of the amine functionality of the linker molecules during TG analysis, was integrated. The areas obtained by this method steadily increase with increasing amount of $\mathrm{H}_{2}$ amineBPDC. Obviously, 

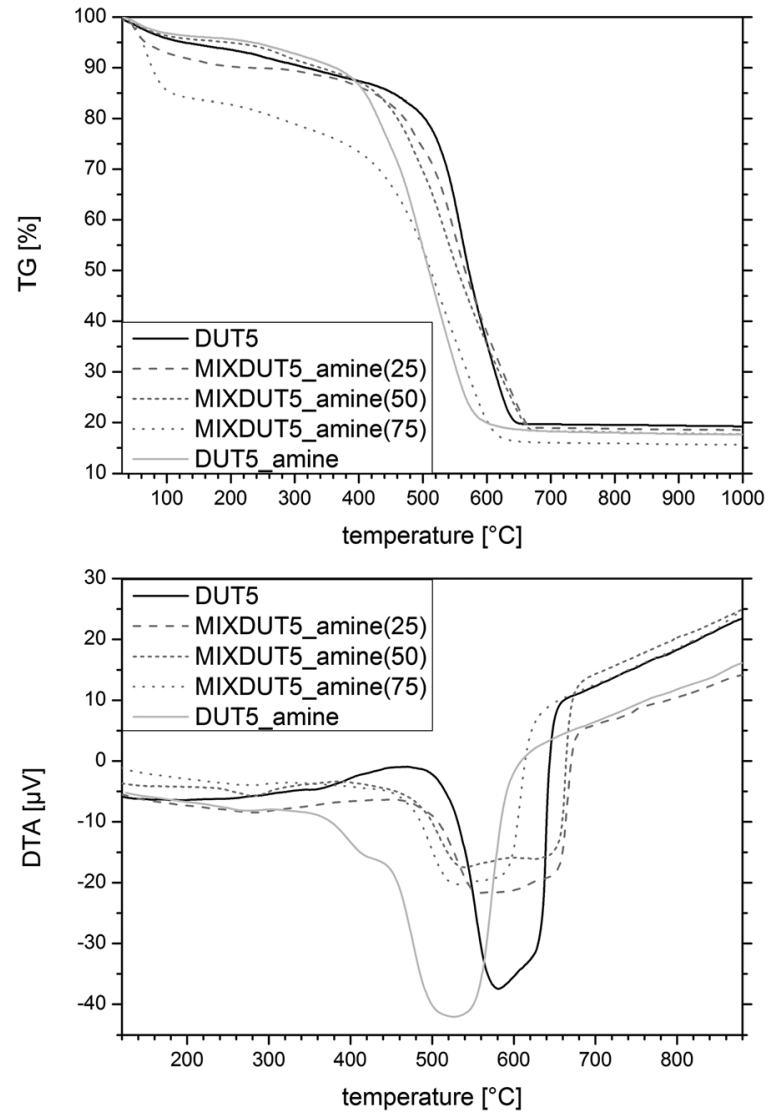

Fig. 3 Thermogravimetric (top) and DTA analyses (bottom) of DUT-5, DUT-5-amine and MIXDUT-5-amine $(x)$ carried out in air.

the ratio of the amine-functionalized and unfunctionalized linker molecules in the MIXDUT-5-amine $(x)$ materials is in good agreement with the ratio that was applied during synthesis. Moreover, the maximum of the integrated peak area of the $\mathrm{CO}_{2}$ band is shifted to lower temperatures for the materials with increasing functionalization degree, which also confirms the slightly reduced thermal stability of the amine-containing frameworks.

NMR measurements of the dissolved frameworks were carried out to quantify the linker ratios in the MIXDUT materials. In a previous study conducted with MIXMIL-53amine $(x)$, it was possible to quantify the linker ratios confirming that the real and theoretical ratio matched very well. ${ }^{49}$ For MIXDUT-5-nitro(50), the ratio detected by NMR spectroscopy (Fig. 4) matched the applied ratio perfectly. However, for the amine-, alkyne- and azide-functionalized materials quantification proved to be difficult due to the strong overlap of the signals of the different linker molecules in the aromatic region of the NMR spectrum. Moreover, a small fraction of the amine groups might have reacted with the solvent ( $N, N$-dimethylformamide). Similar observations have recently been reported for the NMR spectra of amine-functionalized UiO-67, which features 2,2'-diaminobiphenyl-4,4'-dicarboxylate linkers. ${ }^{34}$ Nonetheless, the signals can qualitatively be assigned to the

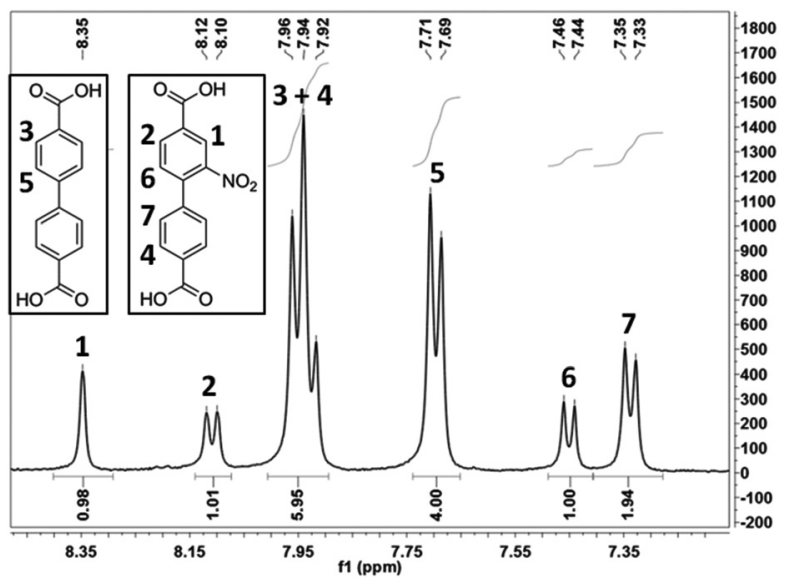

Fig. 4 NMR spectrum of MIXDUT-5-nitro(50) dissolved in $\mathrm{NaOH} / \mathrm{D}_{2} \mathrm{O}$.

functionalized and unfunctionalized molecules, therefore again proving the presence of both linker molecules.

Since ATR-IR spectra, $\mathrm{N}_{2}$ physisorption measurements, TG analyses and NMR spectra all strongly suggest the successful incorporation of the functionalized linker molecules, we claim that the synthesis of amine- and alkyne-functionalized metalorganic frameworks based on the structure of DUT-5 and mixed-linker MOFs with a combination of modified and nonfunctionalized linker molecules was successful. The synthesis of nitro-functionalized MIXDUT-5 was successful, although XRD and $\mathrm{N}_{2}$ physisorption measurements suggest a low crystallinity of the material. The disappearance of the azide band (ATR-IR) strongly indicates that the azide group was not stable under the applied reaction conditions. This fact is corroborated by the appearance of an additional band around $3436 \mathrm{~cm}^{-1}$, which could be ascribed to the $\mathrm{N}-\mathrm{H}$ stretching vibration of a carbazole that was formed under the applied reaction conditions. The low crystallinity (XRD) and porosity ( $\mathrm{N}_{2}$ physisorption) of the azide-functionalized frameworks might be due to the slightly bent geometry of this linker molecule.

\section{Post-synthetic modification}

After thorough characterization of all materials, the functional groups in the mixed-linker metal-organic frameworks were modified in post-synthetic modification (PSM) reactions. In a previous study on MIL-53-amine ${ }^{48}$ a significant drop of the specific surface area from $980 \mathrm{~m}^{2} \mathrm{~g}^{-1}$ to only $150 \mathrm{~m}^{2} \mathrm{~g}^{-1}$ was observed throughout the modification process with maleic anhydride. This trend could be reduced by using MIXMIL-53amine $(x)$ instead of pure MIL-53-amine as starting material. Thus, the modified material still exhibited a specific surface area of approx. $500 \mathrm{~m}^{2} \mathrm{~g}^{-1}$. ${ }^{49}$ Using MIXDUT-5 materials with a larger pore diameter for the PSM reaction should further minimize the pore blocking. Moreover, the syntheses of the functionalized linker molecules are expensive and, thus, applying MIXDUTs with a reduced number of those linkers also has the advantage of decreasing the production costs. 


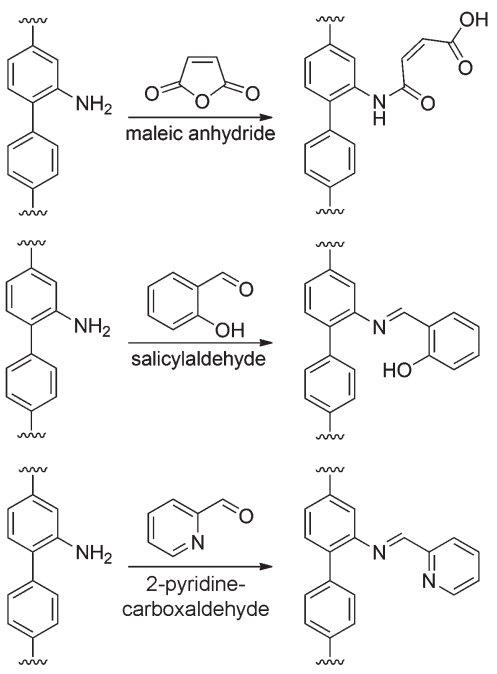

Scheme 4 Post-synthetic modification of MIXDUT-5-amine(50) with maleic anhydride (top), salicylaldehyde (middle) and 2-pyridinecarboxaldehyde (bottom).

MIXDUT-5-amine(50) was modified using maleic anhydride (Mal), salicylaldehyde (Sal) and 2-pyridinecarboxaldehyde (Pyal), respectively (Scheme 4).

In all three cases, X-ray diffractometry proved that the structure of the starting material was preserved throughout the modification reaction without significant loss of crystallinity (Fig. S5 $\dagger$ ). Obviously, the framework structure was stable under the applied PSM reaction conditions.

The specific surface area did not change substantially for the materials modified with salicylaldehyde $\left(1610 \mathrm{~m}^{2} \mathrm{~g}^{-1}\right)$ or 2-pyridinecarboxaldehyde $\left(1600 \mathrm{~m}^{2} \mathrm{~g}^{-1}\right)$, while a reduction of the specific surface area from $1630 \mathrm{~m}^{2} \mathrm{~g}^{-1}$ to $1200 \mathrm{~m}^{2} \mathrm{~g}^{-1}$ was discovered for the PSM with maleic anhydride (Table 4 and Fig. S19†). However, the specific surface area of MIXDUT-5amine(50) only decreased by approx. $25 \%$ throughout the reaction with maleic anhydride, whereas in previous studies the specific surface area of MIXMIL-53-amine(50) with smaller pores was reduced by approx. $50 \%\left(980 \mathrm{~m}^{2} \mathrm{~g}^{-1}\right.$ vs. $\left.500 \mathrm{~m}^{2} \mathrm{~g}^{-1}\right)$ under the same modification conditions. Therefore, the pore system of all modified frameworks should still be accessible.

ATR-IR measurements (Fig. S12†) of MIXDUT-5-amine(50)Mal showed an additional band at $1690 \mathrm{~cm}^{-1}$, which could be

Table 4 Specific surface areas and micropore volumes of modified MIXDUT-5-amine(50) and MIXDUT-5-alkyne(50)

\begin{tabular}{lll}
\hline Material & $\begin{array}{l}S_{\mathrm{BET}} \\
{\left[\mathrm{m}^{2} \mathrm{~g}^{-1}\right]}\end{array}$ & $\begin{array}{l}\text { Micropore volume } \\
{\left[\mathrm{cm}^{3} \mathrm{~g}^{-1}\right]}\end{array}$ \\
\hline MIXDUT-5-amine(50) & 1630 & 0.58 \\
MIXDUT-5-amine(50)-Mal & 1200 & 0.43 \\
MIXDUT-5-amine(50)-Sal & 1610 & 0.64 \\
MIXDUT-5-amine(50)-Pyal & 1600 & 0.59 \\
MIXDUT-5-alkyne(50) & 1350 & 0.42 \\
MIXDUT-5-alkyne(50)-Pyaz & 250 & 0.04
\end{tabular}

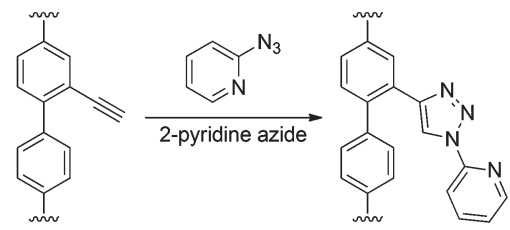

Scheme 5 Post-synthetic modification of MIXDUT-5-alkyne(50) with 2-pyridine azide.

ascribed to the $\mathrm{C}=\mathrm{O}$ vibration of the modified side chain. In the spectra of MIXDUT-5-amine(50)-Sal and MIXDUT-5-amine(50)-Pyal additional bands could not be found. Due to the low intensity of the $\mathrm{N}-\mathrm{H}$ vibrations even in the starting material MIXDUT-5-amine(50), the successful modification could not be confirmed based on a reduction of the intensity of these bands.

MIXDUT-5-alkyne(50) was applied in a copper-catalyzed click reaction with 2-pyridine azide (Pyaz) (Scheme 5).

XRD (Fig. S6†) showed that the crystallinity of the MOF was diminished considerably under the applied reaction conditions, while $\mathrm{N}_{2}$ physisorption measurements (Table 4 and Fig. S20†) revealed a very low specific surface area of only $250 \mathrm{~m}^{2} \mathrm{~g}^{-1}$ after PSM. These results suggest that MIXDUT-5alkyne(50) might not be stable under the given reaction conditions and that this modification pathway needs to be optimized.

\section{Conclusions}

In summary, four functionalized linker molecules based on 4,4'-biphenyldicarboxylic acid with an additional amine, alkyne, nitro or azide group were prepared. Those linker molecules were successfully applied in the synthesis of novel functionalized metal-organic frameworks isoreticular to the DUT-5 structure which was confirmed by XRD. ATR-IR spectroscopy confirmed that the functionalities except the azide group (formation of a carbazole) were stable under the applied reaction conditions and present in the resulting framework materials. $\mathrm{N}_{2}$ physisorption proved that the amine- and alkyne-functionalized frameworks were highly porous $\left(1570 \mathrm{~m}^{2} \mathrm{~g}^{-1}\right.$ and $1270 \mathrm{~m}^{2} \mathrm{~g}^{-1}$, respectively) and thermogravimetric analysis showed that all functionalized materials were stable in air up to at least $370{ }^{\circ} \mathrm{C}$.

Additionally, crystalline mixed-linker metal-organic frameworks with varying ratios of functionalized and unfunctionalized linker molecules were prepared. This approach is advantageous since the properties of the frameworks can be tuned depending on the linker ratio. $\mathrm{N}_{2}$ physisorption showed that for the amine-functionalized material the surface area increased steadily (from $1570 \mathrm{~m}^{2} \mathrm{~g}^{-1}$ to $1880 \mathrm{~m}^{2} \mathrm{~g}^{-1}$ ) with decreasing percentage of functionalized linker molecules incorporated in the framework materials. Thermogravimetric analysis revealed that the thermal stability of all functionalized materials decreased with increasing degree of functionali- 
zation. ATR-IR spectroscopy also strongly indicated the successful incorporation of the functionalized linker molecules into the MIXDUTs. For MIXDUT-5-nitro(50) the actual linker ratio in the framework and the ratio applied during synthesis matched perfectly which could be proven by ${ }^{1} \mathrm{H}$ NMR. Additionally, TG-IR measurements of the MIXDUT-5-amine $(x)$ series confirmed that the linker ratios in the amine-functionalized materials matched the applied ratios very well.

Finally, post-synthetic modification of MIXDUT-5-amine(50) was achieved with maleic anhydride, salicylaldehyde and 2-pyridinecarboxaldehyde. Both the crystallinity and, most importantly, the porosity $\left(1200 \mathrm{~m}^{2} \mathrm{~g}^{-1}\right.$ to $\left.1600 \mathrm{~m}^{2} \mathrm{~g}^{-1}\right)$ of the frameworks could be retained throughout the modification process.

In future applications the novel framework materials might be used for gas storage or separation due to the changed hostguest interactions arising from the additional functional groups. Another possibility is the immobilization of mononuclear metal complexes on the functionalities in the framework materials to obtain heterogeneous catalyst materials featuring well-defined single-sites.

\section{Acknowledgements}

A. Beilmann is acknowledged for performing the TG-IR measurements. We thank Prof. J.-D. Grunwaldt for providing the instrument for TG-IR analysis, Prof. C. Feldmann for providing the instrument for TG analysis and Prof. P. W. Roesky for providing the NMR spectrometer. The DFG is acknowledged for funding the TG-IR instrument. T. S. Brunner thanks the Helmholtz Research School Energy-related Catalysis and the FCI for financial support.

\section{Notes and references}

1 M. O'Keeffe, Chem. Soc. Rev., 2009, 38, 1215-1217.

2 J. R. Long and O. M. Yaghi, Chem. Soc. Rev., 2009, 38, 12131214.

3 S. T. Meek, J. A. Greathouse and M. D. Allendorf, Adv. Mater., 2011, 23, 249-267.

4 H.-C. J. Zhou and S. Kitagawa, Chem. Soc. Rev., 2014, 43, 5415-5418.

5 V. Guillerm, D. Kim, J. F. Eubank, R. Luebke, X. Liu, K. Adil, M. S. Lah and M. Eddaoudi, Chem. Soc. Rev., 2014, 43, 6141-6172.

6 S. Kitagawa, R. Kitaura and S.-i. Noro, Angew. Chem., Int. Ed., 2004, 43, 2334-2375.

7 J. L. C. Rowsell and O. M. Yaghi, Microporous Mesoporous Mater., 2004, 73, 3-14.

8 G. Ferey, Chem. Soc. Rev., 2008, 37, 191-214.

9 C. Janiak and J. K. Vieth, New J. Chem., 2010, 34, 23662388.

10 N. Stock and S. Biswas, Catal. Rev., 2012, 112, 933-969.
11 H. Furukawa, K. E. Cordova, M. O'Keeffe and O. M. Yaghi, Science, 2013, 341, 1230444.

12 I. Senkovska and S. Kaskel, Chem. Commun., 2014, 50, 7089-7098.

13 M. J. Ingleson, J. P. Barrio, J.-B. Guilbaud, Y. Z. Khimyak and M. J. Rosseinsky, Chem. Commun., 2008, 2680-2682.

14 A. D. Burrows, C. G. Frost, M. F. Mahon and C. Richardson, Angew. Chem., Int. Ed., 2008, 47, 8482-8486.

15 Z. Wang and S. M. Cohen, Chem. Soc. Rev., 2009, 38, 13151329.

16 K. K. Tanabe and S. M. Cohen, Chem. Soc. Rev., 2011, 40, 498-519.

17 A. D. Burrows and L. L. Keenan, CrystEngComm, 2012, 14, 4112-4114.

18 J. D. Evans, C. J. Sumby and C. J. Doonan, Chem. Soc. Rev., 2014, 43, 5933-5951.

19 H. Li, M. Eddaoudi, M. O'Keeffe and O. M. Yaghi, Nature, 1999, 402, 276-279.

20 M. Eddaoudi, J. Kim, N. Rosi, D. Vodak, J. Wachter, M. O'Keeffe and O. M. Yaghi, Science, 2002, 295, 469-472.

21 T. Loiseau, C. Serre, C. Huguenard, G. Fink, F. Taulelle, M. Henry, T. Bataille and G. Ferey, Chem. - Eur. J., 2004, 10, 1373-1382.

22 A. Comotti, S. Bracco, P. Sozzani, S. Horike, R. Matsuda, J. Chen, M. Takata, Y. Kubota and S. Kitagawa, J. Am. Chem. Soc., 2008, 130, 13664-13672.

23 T. Ahnfeldt, D. Gunzelmann, T. Loiseau, D. Hirsemann, J. Senker, G. Ferey and N. Stock, Inorg. Chem., 2009, 48, 3057-3064.

24 D. Himsl, D. Wallacher and M. Hartmann, Angew. Chem., Int. Ed., 2009, 48, 4639-4642.

25 C. Volkringer, T. Loiseau, N. Guillou, G. Férey, M. Haouas, F. Taulelle, E. Elkaim and N. Stock, Inorg. Chem., 2010, 49, 9852-9862.

26 S. Biswas, T. Ahnfeldt and N. Stock, Inorg. Chem., 2010, 50, 9518-9526.

27 W. Kleist, F. Jutz, M. Maciejewski and A. Baiker, Eur. J. Inorg. Chem., 2009, 3552-3561.

28 W. Kleist, M. Maciejewski and A. Baiker, Thermochim. Acta, 2010, 499, 71-78.

29 S. Marx, W. Kleist, J. Huang, M. Maciejewski and A. Baiker, Dalton Trans., 2010, 39, 3795-3798.

30 H. Deng, C. J. Doonan, H. Furukawa, R. B. Ferreira, J. Towne, C. B. Knobler, B. Wang and O. M. Yaghi, Science, 2010, 327, 846-850.

31 Y. Jiang, J. Huang, S. Marx, W. Kleist, M. Hunger and A. Baiker, J. Phys. Chem. Lett., 2010, 1, 2886-2890.

32 A. D. Burrows, CrystEngComm, 2011, 13, 3623-3642.

33 D. N. Bunck and W. R. Dichtel, Chem. - Eur. J., 2013, 19, 818-827.

34 N. Ko, J. Hong, S. Sung, K. E. Cordova, H. J. Park, J. K. Yang and J. Kim, Dalton Trans., 2015, 44, 2047-2051.

35 S. J. Garibay, Z. Wang, K. K. Tanabe and S. M. Cohen, Inorg. Chem., 2009, 48, 7341-7349.

36 S. J. Garibay, Z. Wang and S. M. Cohen, Inorg. Chem., 2010, 49, 8086-8091. 
37 E. Dugan, Z. Wang, M. Okamura, A. Medina and S. M. Cohen, Chem. Commun., 2008, 3366-3368.

38 Y. Goto, H. Sato, S. Shinkai and K. Sada, J. Am. Chem. Soc., 2008, 130, 14354-14355.

39 M. Savonnet, A. Camarata, J. Canivet, D. Bazer-Bachi, N. Bats, V. Lecocq, C. Pinel and D. Farrusseng, Dalton Trans., 2012, 41, 3945-3948.

40 G. Tuci, A. Rossin, X. Xu, M. Ranocchiari, J. A. van Bokhoven, L. Luconi, I. Manet, M. Melucci and G. Giambastiani, Chem. Mater., 2013, 25, 2297-2308.

41 T. Gadzikwa, G. Lu, C. L. Stern, S. R. Wilson, J. T. Hupp and S. T. Nguyen, Chem. Commun., 2008, 5493-5495.

42 Z. Wang, K. K. Tanabe and S. M. Cohen, Chem. - Eur. J., 2010, 16, 212-217.

43 S. Couck, J. F. M. Denayer, G. V. Baron, T. Rémy, J. Gascon and F. Kapteijn, J. Am. Chem. Soc., 2009, 131, 6326-6327.

44 S. Couck, E. Gobechiya, C. E. A. Kirschhock, P. SerraCrespo, J. Juan-Alcañiz, A. Martinez Joaristi, E. Stavitski, J. Gascon, F. Kapteijn, G. V. Baron and J. F. M. Denayer, ChemSusChem, 2012, 5, 740-750.

45 J. Gascon, U. Aktay, M. D. Hernandez-Alonso, G. P. M. van Klink and F. Kapteijn, J. Catal., 2009, 261, 75-87.

46 M. G. Goesten, J. Juan-Alcañiz, E. V. Ramos-Fernandez, K. B. Sai Sankar Gupta, E. Stavitski, H. van Bekkum, J. Gascon and F. Kapteijn, J. Catal., 2011, 281, 177-187.

47 T. Lescouet, C. Chizallet and D. Farrusseng, ChemCatChem, 2012, 4, 1725-1728.
48 M. A. Gotthardt, A. Beilmann, R. Schoch, J. Engelke and W. Kleist, RSC Adv., 2013, 3, 10676-10679.

49 M. A. Gotthardt, R. Schoch, T. S. Brunner, M. Bauer and W. Kleist, ChemPlusChem, 2015, 80, 188-195.

50 E. D. Bloch, D. Britt, C. Lee, C. J. Doonan, F. J. Uribe-Romo, H. Furukawa, J. R. Long and O. M. Yaghi, J. Am. Chem. Soc., 2010, 132, 14382-14384.

51 F. Carson, S. Agrawal, M. Gustafsson, A. Bartoszewicz, F. Moraga, X. Zou and B. Martín-Matute, Chem. - Eur. J., 2012, 18, 15337-15344.

52 H. Liu, B. Yin, Z. Gao, Y. Li and H. Jiang, Chem. Commun., 2012, 48, 2033-2035.

53 I. Senkovska, F. Hoffmann, M. Fröba, J. Getzschmann, W. Böhlmann and S. Kaskel, Microporous Mesoporous Mater., 2009, 122, 93-98.

54 S. Couck, Y.-Y. Liu, K. Leus, G. V. Baron, P. Van der Voort and J. F. M. Denayer, Microporous Mesoporous Mater., 2015, 206, 217-225.

55 S. Halis, N. Reimer, A. Klinkebiel, U. Lüning and N. Stock, Microporous Mesoporous Mater., 2015, 216, 13-19.

56 V. K. Olkhovik, D. A. Vasilevskii, A. A. Pap, G. V. Kalechyts, Y. V. Matveienko, A. G. Baran, N. A. Halinouski and V. G. Petushok, ARKIVOC, 2008, 69-93.

57 K. Barral, A. D. Moorhouse and J. E. Moses, Org. Lett., 2007, 9, 1809-1811.

58 X.-C. Yi, F.-G. Xi, Y. Qi and E.-Q. Gao, $R S C A d v ., 2015,5$, 893-900. 